\title{
THE SOCIAL PRESENCES IN TEXT-BASED COLLABORATIONS VIA ELECTRONIC DEVICES: MEASURING THE 'ONLINE-SELF' OF THE YOUNG GENERATION IN BANGLADESH
}

\author{
Muhammad Rehan MASOOM ${ }^{1}$ \\ Md Nahid ALAM ${ }^{2}$ \\ Rubaiyat Bin ARIF $^{3}$ \\ ${ }^{1}$ School of Business \& Economics, United International University, Dhaka, Bangladesh \\ ${ }^{2}$ School of Business \& Economics, United International University, Dhaka, Bangladesh \\ ${ }^{3}$ School of Business \& Economics, United International University, Dhaka, Bangladesh \\ (C) 2016 Muhammad Rehan Masoom, Md Nahid Alam, Rubaiyat Bin Arif \\ This is an open access article distributed under the Creative Commons Attribution-NonCommercial-NoDerivs license \\ (http://creativecommons.org/licenses/by-nc-nd/3.0/) \\ DOI: 10.1515/eras-2016-0009
}

\begin{abstract}
The procedural revolution of technology making people more and more linked to virtual based lives, and providing an outline to live in online-based curriculums. However, not all the nations have the same level of access and equal opportunities to grip the fruit of communication technology, hence the social presence in cyberspace suppose to differ from nations to nations. The study tends to explore the facets of technologymediated text-based correspondences of the young generation, who often apt to use their own technologically advanced telecommunication devices. To conceptualize the qualitative aspect of the study into quantitative findings, the key assumptions are tested in each step of the factor analysis process. Based on the scanned cases of the survey, the study concludes that the young generation of the nations, where technological advancement is yet to flourish is less formal, more emotionally sensitive and more open about their state of the mind compared to the technologically advanced nations.
\end{abstract}

.Keywords: Text-based conversations, Online-self, young generation, Bangladesh

\section{Introduction}

Social interaction in co-presence, with the feeling of facing the interaction partner or partners, the ambience of the location and sense of the time zone are the foundation bricks of any strong social relation. However, in the world with flooded technological devices and the presence of immense number of social media, and with the necessity to establish longdistance communication for pleasure or purpose, technology-mediated text-based collaboration has become a common incidence of the information age. The pattern of social presence and the formation of social relation may significantly differ between online and offline self-presentation due to the perceived value of the collaboration itself. Real time faceto-face conversation facilitates the anticipation of emotional state of the interaction partner and reaction formation happens to be more spontaneous and less deceptive. The non-verbal cues like facial expressions, posture or body language, and apparently not-so-significant verbal components like voice intonation, silences between words that play significant roles in the formation of real-life social interaction, are virtually absent in text-based collaborations. Despite, these lacking of social context cues, text-based collaboration has become a very 
popular form of communication around the world. Both business and educational organizations, in institutional level and mass people, in personal day-to-day affairs, have to engage in some sorts of text-based collaborations.

There are more than seven billion internet users and slightly less than seven billion cell-phone users around the world at present (International Telecommunication Union, 2014), and these huge numbers of people are, in one form or other, are actual or potential users of text-based communication. They are, in a way, by simply having few technological skills, virtually have the provision to be involved in correspondences with each-other regardless of their regional location and ethnological differences. They can interact through internet or smart-phone without even knowing the language of their interaction partners merely due to the presence of language translating software. This enhanced access to communicate increases the immense number of opportunities in one hand, and at the same time, producing complex pattern of social presence on the other. Due to the absence of social context or having no compulsion of proximity, social actors now have the opportunity to present themselves as they prefer, rather than what they really are. This "virtual reality" offers the space, where one can be as informal as he or she likes, or as anonymous as choose to be with no worries of having spoiled identity. This fascinating venture of constructing a false impression becomes quite evident while, the social media company like FACEBOOK, INC reveals that up to 8.7 percents of the 955 million monthly active users worldwide are actually duplicate or false accounts (CNN, 2012). However, this is not the only picture of the text-based, technologymediated communication. One can fairly protest by posting comments in a web-log, commonly known as blog, or coordinate with business partner to fix a meeting, or sending curriculum vitae to get a desired job or even saying sorry by sending email.

Nonetheless, around the globe, not all countries have the same level of access and equal opportunities to grip the fruit of communication technology; there is a gap between developing and developed nations on an international scale, commonly known as "Digital Divide" (Chinn, \& Fairlie, 2004). The developed countries, from where this new form of communication is originated, have integrated it with their regular lives, whereas the picture is evidently not the same in the developing countries like Bangladesh, where people fairly have the access to be online. The status of information and communication technology in Bangladesh is not remarkably good, and the charge Internet connectivity with acceptable quality and reliability is still quite high (Islam, 2010). Until recently, there was hardly any initiative by the government to improve the telecommunication sector. People of this country, first have got the opportunity to communicate through text via mobile phone devices in 1989, when only two cell-phone connection providing companies have got the license to operate in different parts of the country (BTCL, 2012-13). During the same period, people had dialup access to e-mail using the Bulletin Board Systems (BBSs) through a few local service providers of this line of work. Around 1996, the first 'Very Small Aperture Terminal' (VSAT) base data circuit in the country was commissioned and the Bangladesh Telegraph and Telephone Board (BTTB) granted licenses to two Internet Service Providers (ISPs) (Rahman, 2007). In following years, due to liberal government policies, people of Bangladesh have witnessed an exponential growth of the communication industry throughout the country. Today, near about thirty-five million people of Bangladesh are using internet, and among them 96 percent are accessing through their cellular devices (BTRC, 2014). The total number of Mobile Phone subscribers has reached 114.808 million at the end of January 2014 (BTRC, 2014).

Today, an impressive number of people, who have accessed to internet, through mobile phone or computer, have connected themselves with different social media, commonly FACEBOOK. SOCIALBAKERS (www.socialbakers.com), a social media analytics and 
publishing company reports that almost 2.8 million people of Bangladesh are engaged in using FACEBOOK at present, and among those users, 1.37 million or almost 50 percent belongs to 18-to-24 age-bracket. Another 29 percent of the users are from 25 years to 34 years of age (The Business Habit Blog, 2015). This indicates that the virtual world is now opened up to the people of Bangladesh, and they can also avail the prospect of constructing impressions, both true and false, about themselves through text based correspondences. The online self-presentation is quite likely to be apparent among those, who are young, and have their own personal computers or smart-phones, access to quality internet services and skills to communicate electronically. Further, Dhaka city dweller, especially the young generation with the willingness to avoid the unbearable traffic congestion and intolerable environmental hazard often like to comply with technology-mediated correspondence with their interaction partners, even if they live at the next doors. Those who are studying in private universities, and paying high tuition fees, are, presumably, more likely to have their personal computers or smart phones and heavy users of internet as well as text-based communication than that of the students of public universities, where tuition fees mostly state-funded. The study explores the facets of technology-mediated text-based correspondences of the young generation, who are living in Dhaka and apt to use their own technologically advanced telecommunication devices.

\section{Literature Review}

The study of Kiesler, Siege \& McGuire (1984) is one of the pioneering studies to address the issue of the social psychological aspects of Computer-mediated Communication $(\mathrm{CMC})$. They indicate, CMC may have technical advantages like rapid sharing of information, efficiency to communicate with a large number of people simultaneously, and adaptability of written text, but it lacks both formal and informal etiquette of proper social contact. CMC involves a process of depersonalization, and hence an individual becomes "more responsive to immediate textual cues, more impulsive and assertive, and less bound by precedents set by societal norms" (Kiesler, Siege \& McGuire, 1984, p. 1130). Sproull \& Kiesler (1986) argue that decreasing social context cues in the electronic mail has significant deregulating effects due to the self-absorption, status equalization, and uninhibited behavior of the communicators. Individual's behavior tends to be relatively other-focused, differentiated, and controlled in the presence of strong social cues, whereas the absence of cues result in anonymity, and the behavior of the same individual become relatively self-absorbed and unregulated. Further, Judith Donath (1995) indicates, the vast growth of electrical communication indulges the phenomenon of deceiving identities in the respective online communities. Identity deception is a complex concept as it creates a perplexing attitude both in the real world and to the online environment. Online permanent identities or temporary virtual persona depends on the virtual contexts. Therefore, the importance of identity to various assemblages varies from being obligatory to being cheap. Hence, online communities more often than not form their identities based on the specific concerns of what is required.

Malcolm Parks and Lynne Roberts (1997) say that the number of forming personal relationships is very high in the cyberspace. It provides a unique and powerful context of forming diversified relationships. Their study compares the online image projection and offline reality. The imagination of the other individuals' appearance and gesture play a crucial role in forming expectation in CMC. However, imagination often differs from that of the reality. In an article about online dating (Hamilton 1999), one common complaint was, "It's draining when you realize how different people are from what they project online." Hence, building trust is a tough task to accomplish in CMC. Wilson, Straus \& McEvily (1999) 
indicate that developing trust in CMC takes comparatively longer period as there is no tangible projected appearance of the real individual. Karen Douglas and Craig McGarty (2001) express that individuals tend to interact in an aggressive manner, which they call 'the flaming behavior'. Behaviors are often hostile or insulting in $\mathrm{CMC}$, as Amichai-hamburger, Wainapel, \& Shaulfox (2002) point out that the internet helps the introvert or neurotic groups to express their 'real me'. Cyberspace gives opportunities to interact with various groups of people to those who otherwise face difficulties in real life face-to-face interactions due to their introverted personality. Hence, to the introverts, virtual life is a great replacement of the 'reallife' and gives platform to express their 'digressive self'. In addition, Scott Caplan (2003) indicates that mentally stressed, depressed or lonely individuals tend to create adverse outcome due to their problematic behavior in Cyberspace. Therefore, people who prefer to socialize themselves through the internet rather than face-to-face communication face negative consequences associated with problematic internet users.

The study of Susan Brown, Robert Fuller \& Chelley Vician (2004) deals with the anxiety of communication apprehension in CMC. They outlined the fear of apprehension associated with the actual or anticipated use of information technology to communicate with others. Constructs of computer anxiety, Communication apprehension, and CMC familiarity have a huge variance of attitudes rather than familiarity. Nicholas Epley and Justin Kruger (2004) deal with the uneven fidelity of the modes of communication for building impression through CMC. They deal with componential differences between e-mail and voice-based interactions as a medium of communicating. These distinctions are created for some distinct stereotyping expectations. Their experiments demonstrate that racial stereotypes and artificial likelihoods affect people's impressions of a target more strongly over e-mail than that of voice interactions. The word-to-word content is often misleading, and email has more ambiguity than that of the voice communications, hence electronic form of communication has unexpected detriments. A new study of Scott Caplan (2005) indicates that individuals who lack the social skills of self-presentation are more likely to use online communication system rather than face-to-face conversation. For this, there is a compulsive use of the internet, which results in adverse outcomes. However, in contrast to this, Peter, Valkenburg, \& Schouten (2005) indicate, compared with the introverts, extroverts are more self-disclosed and busy to communicate online more often than that of the others. CMC format opens a new window for communication, and to the extroverts, online communication do not differ much to them from their actually interactions encountered in the face-to-face situations.

Ellison, Heino \& Gibbs (2006) consider online 'self-presentation' as an adapted strategy, based on the form of dating. They explain how communicators manage themselves to find a romantic partner. Individuals give humble cues as a tactic to form their impression and tend to create a profile that reflects their "ideal self."Jennifer Gibbs, Nicole Ellison and Rebecca Heino (2006) investigate the self-disclosure in online dating relationships. They found that four dimensions of self-disclosure, such as honest, amount, intent, and valence could predict perceived online dating successes. Stephen Rains and Craig Scott (2007) discuss the anonymous online communication and how a receiver responses to it. The diversification of the context of communication, the source, the receivers longing of identifying the source and the ability of the receiver to determine the source affects the receivers' attempt of establishing the contact. The identification or the anonymity of the messages of whether it is beneficial or problematic determines the level of response.

Joseph Walther (2007) outlines the technological aspects of the exploitation of CMC. He indicates that the construction of impression varies in responses to the targeted groups and gender or status interactions. Internet users control message-composing time, manipulate behaviors, edit languages or sentence complexity, and relational tone in their initial messages 
in regard to the targeted groups. Danah Boyd (2007) studies impression management in the virtual world where a majority of our teenagers spend a lot of their times, today. Teenagers are socializing themselves in an online-community with unfamiliar others, learning the social regulations through the online interactive process. Amy Gonzales \& Jeffrey Hancock (2008) point out that although the internet as being a form of personal expression is becoming a widespread attribute, nonetheless online presentation has no power to change our personalities. The digressive shift of an individual's identity from face-to-face to CMC may influence the future interaction contexts. Not all researchers point out the negativity of the usage of online-communication. Yair Amichai-Hamburger (2005) explains how the internet can be used to help to rehabilitate the homeless, addict, stigmatized, introverts or even neurotic group of people or individuals despite their disadvantaged position. These disadvantaged people feel protected gain the strength in the virtual world that eventually make a difference in their real life. Further, Daantje Derks, Arjan Bos and Jasper von Grumbkow (2007) define the use of emoticons as an expression of emotions and the state of the mind in internet communication. Emoticons are basic facial expressions of true emotions for the users of CMC interface. Individuals intend to use more emoticons in socio-emotional contexts rather than work oriented frameworks.

\section{Methods}

The study investigates the aspects of the social presence in the text-based collaboration through the internet; hence, the research design is made to quantify the real life qualitative data that are collected directly from the respondents. The study initially applies factor analysis to identify the components that summarize the qualitative traits of the responses. Hence, the research follows a detail step-by-step process of factor analysis and generalization of data that are consistent with primary research objective as well as sufficient understanding of secondary objectives. Besides, the analysis adds some objectivity in the descriptive nature of the study. However, working with qualitative data and questionnaire in a developing setting like Bangladesh is often challenging, because adequate and appropriate responses are often difficult to obtain as expected for empirical research purposes. In addition, there is a general limitation of non-response error in any empirical questionnaire survey. Gujrati (1997) states that the empirical researcher often gets about 40 percent responses and that may affect the true pattern of the behavior of the respondents. Keeping these barriers in mind, the study adopts the questionnaire from the work of Mathews A. R. (2006) in a more flexible way to collect the responses. To maintain the integrity of the response the entire data collection process is monitored by the surveyors. All data are collected directly from the primary respondents.

The study emphasizes the data integrity and adequacy while designing the sample to fulfill the requirements of the psychometric tests. For the questionnaire, survey respondents are selected from the undergraduate students from the universities located in Dhaka. The primary reason behind the selection of sample is that younger generation is assumed to be using the internet more regularly than the rest. For that, five universities are selected, that are North South University (NSU, n=124), University of Liberal Arts (ULAB, n=98), United International University (UIU, $n=110)$, East West University (EWU, $n=112$ ) and Independent University Bangladesh (IUB, $\mathrm{n}=78$ ). However, a problem of non-random sample arises, when the survey is conducted on selective group of respondents, hence, loses some aspect of generalization. To mitigate this matter, 385 respondents of 532 among the cluster are selected randomly for analysis of the study. This process of converting non-random sample into random sample is adopted from the method suggested by Wooldridge (2009). Therefore, the 
sample contained adequate randomness and asymptotic properties that are important to draw generalize conclusions.

The model designed for this study contains both analytical and conceptual understanding of the research objectives. Therefore, explanatory factor analysis is used as the key analytical tool for the study. However, to conceptualize the qualitative aspect of the study into quantitative findings, the key assumptions are tested in each step of the factor analysis process. To ensure the verifiability, the factor analysis is conducted using software packages like SPSS and STATA. From the projected pre-factor analysis item mapping based on technological industry scale from Mathews A.R. (2006), seven factors are selected, and thirtyfive questions are categorized under each of the appropriate categories. The reliability of the questions included under each item is tested using Cronbach's alpha. The questions pass the reliability tests are carried forward to the later stages. For data reduction, exploratory factor analysis is conducted using principal component analysis extraction method. In addition, varimax method of loading with Kaiser Normalization is used for factor rotation. The standard testing criteria is used throughout the factor analysis process to ensure the validity and reliability of findings. Besides, the KMO test is conducted to test sampling adequacy in the factor analysis process, and Monte-Carlo PCA technique is used to compare the variances for the factor selection process (Girden, E. R., 2001). The process of aforementioned step is repeated using the surviving factors to draw a generalize findings under those factors. The process is repeated until the optimum number of factors is found that can adequately capture the features of data. The entire process is conducted in such a way that both the results and the assumptions for the analysis are tested in each stage.

\section{Results \& Discussions}

Amanda Robyn Matthews (2006) in her PhD dissertation titled, "The Technological Insularity Scale: A Scale Development" offers seven factors, thirty-five questions categorized under the appropriate categories. The study uses that as the projected pre-factor item mapping. (The summary of the categorization is given in table 1; please see Appendix 1 for the lists of all the items) 


\begin{tabular}{|c|c|c|}
\hline Item & Definition & Item Number \\
\hline Informality & $\begin{array}{l}\text { The degree of attention or inattention to linguistic formalities i.e. } \\
\text { sentence structure, grammar, syntax and so on, when conversing or } \\
\text { emailing, one's }\end{array}$ & $1,8,15,22,29$ \\
\hline Sensitivity & $\begin{array}{l}\text { The extent of whether or not the communicator is cognizant of the } \\
\text { potential impact of what is being said on the recipient(s) during } \\
\text { conversation or email. }\end{array}$ & $2,9,16,23,30$ \\
\hline Regulation & $\begin{array}{l}\text { The extent, to which content, form, or affective characteristics of a } \\
\text { conversation or email are tailored, based on actual, anticipated, or } \\
\text { imagined characteristics of the recipient(s). }\end{array}$ & $3,10,17,24,31$ \\
\hline $\begin{array}{l}\text { Disclosure } \\
\text { (Openness) }\end{array}$ & $\begin{array}{l}\text { (a) The level of willingness of communicators to disclose personal or } \\
\text { private information in conversations or emails; } \\
\text { (b) The extent to which openness and honesty of expression } \\
\text { characterizes those communications. }\end{array}$ & $4,11,18,25,32$ \\
\hline Emotionality & $\begin{array}{l}\text { The extent to which exaggerated or inappropriate emotional expression } \\
\text { or affective tone is used in conversation or e-mail. }\end{array}$ & $5,12,19,26,33$ \\
\hline $\begin{array}{l}\text { Anonymity } \\
\text { (Depersonalization) }\end{array}$ & $\begin{array}{l}\text { The degree to which conversations or emails are felt to be impersonal } \\
\text { or private. }\end{array}$ & $6,13,20,27,34$ \\
\hline Homogeneity & $\begin{array}{l}\text { The extent to which the form or content of conversations or emails are } \\
\text { differentiated by the communicator based on the status or position of } \\
\text { the recipient(s). }\end{array}$ & $7,14,21,28,35$ \\
\hline
\end{tabular}

Table 1 Initial factor definition and related arrangement of items

\section{Source: Mathews A.R. (2006)}

The reliability statistics of Cronbach's Alpha for each of the item and the alpha if any question is deleted to enhance the reliability of the data need to be analyzed before proper measurement. Almost all of the items have Cronbach's Alpha more than 0.6 except the items: emotionality and homogeneity, this indicates an acceptable limit of the reliability of the data set as per general practice. However, the reliability of the item 'Regulation' can be improved if the question number 10 is excluded from the current sample resulting in the Cronbach's Alpha of 0.668 which is higher than that of the original five items. Similarly, the Cronbach's Alpha of the item 'Emotionality' improves from 0.548 to 0.589 if the question number 12 is dropped, and for the item 'Homogeneity' it improves from 0.563 to 0.580 if the question number 35 is omitted. Besides, question number 14 and 31 are also excluded from further analysis as absence of both will increase reliability of their respective item. (Please, see table 2 for detail)

\begin{tabular}{|c|c|c|c|c|c|}
\hline \multicolumn{2}{|l|}{ Item } & \multicolumn{4}{|c|}{ Question Number with Alpha if Deleted } \\
\hline Informality & 1 & 8 & 15 & 22 & 29 \\
\hline Cronbach's Alpha (0.659) & 0.613 & 0.587 & 0.583 & 0.602 & 0.631 \\
\hline Sensitivity & 2 & 9 & 16 & 23 & 30 \\
\hline Cronbach's Alpha (0.648) & 0.594 & 0.610 & 0.618 & 0.579 & 0.564 \\
\hline Regulation & 3 & 10 & 17 & 24 & 31 \\
\hline Cronbach's Alpha (0.655) & 0.621 & 0.668 & 0.508 & 0.546 & 0.657 \\
\hline Disclosure & 4 & 11 & 18 & 25 & 32 \\
\hline Cronbach's Alpha (0.618) & 0.569 & 0.536 & 0.585 & 0.611 & 0.608 \\
\hline Emotionality & 5 & 12 & 19 & 26 & 33 \\
\hline Cronbach's Alpha (0.548) & 0.518 & 0.589 & 0.417 & 0.485 & 0.487 \\
\hline
\end{tabular}




\begin{tabular}{|c|c|c|c|c|c|}
\hline Anonymity & 6 & 13 & 20 & 27 & 34 \\
\hline Cronbach's Alpha $(0.646)$ & 0.591 & 0.581 & 0.561 & 0.575 & 0.639 \\
\hline Homogeneity & 7 & 14 & 21 & 28 & 35 \\
\hline Cronbach's Alpha (0.563) & 0.461 & 0.564 & 0.489 & 0.488 & 0.580 \\
\hline
\end{tabular}

Table 2 Summary of Data reliability with Cronbach's alpha

From initial solution of the factor analysis using the remaining questions, results indicate that the 11 components have eigen value more than 1 and explain about 58 percent of the variance of the components. The results are consistent with the Monte-Carlo PCA simulation that also provides the evidence for those 11 components. The component matrix indicates that more than 50 percent of the characteristics can be explained using these 11 components. The study uses simulation with different combination of components and from that simulation, it is expected that six components are more useful in describing the characteristics of the sample data. However, using six components has some drawbacks: these components explain less than $40 \%$ of the characteristics if all the questions for initial solution are used. To solve this problem, the questions having uniqueness more than 60 percent are excluded from six components factor analysis. Using this process question number $1,2,7,9,21,30$ and 34 are not used for six components factor solution. The scree plot and score plot using six components factor analysis are given below:
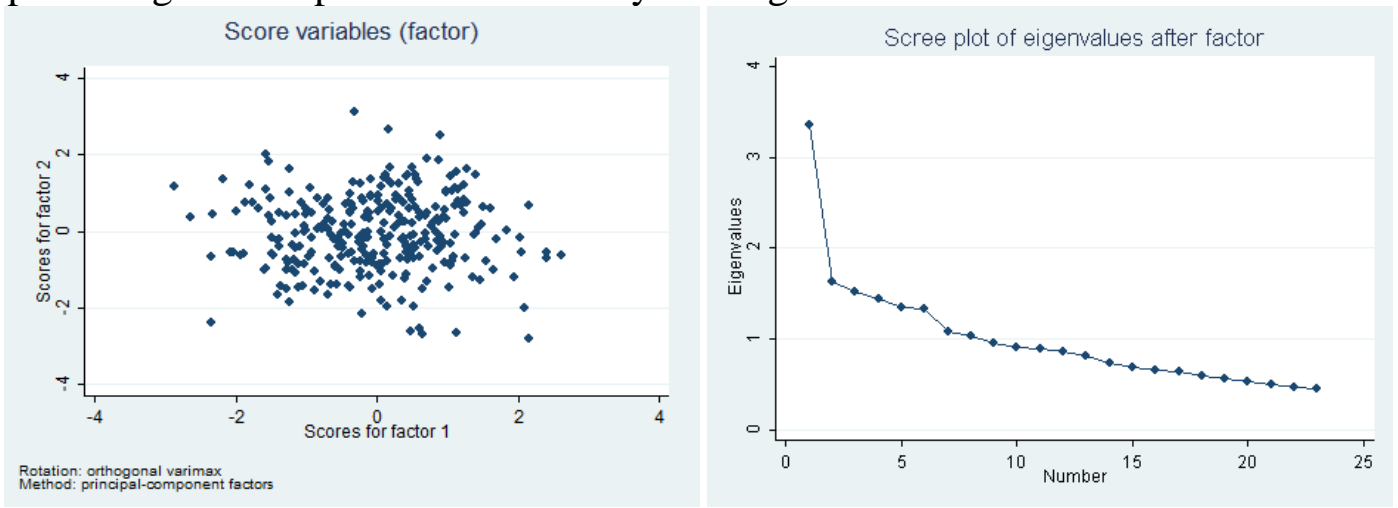

Figure 1. Scree plot and Score plot for six-component factor analysis

All the questions included in the analysis explain more than forty percent characteristics of the sample. It also indicates the component 4 can be described by the highest number of unique solutions of four questions, followed by component 1, 2 and 3, each can be explained by three unique questions. The component 5 has the lowest number of questions - two questions only. The components can be generalized based on the characteristics of their relevant questions. Although some questions may appear under different categories from the initial seven items (mentioned in Table-1), the findings are consistent with the existing theories. Nevertheless, the results of this six components factor analysis explore new areas for further studies.

The rotated score plot suggests that there is no significant outliers in the six component factor analysis. This finding regarding absence of significant outliers provides an added advantage for the further analysis of this study. In addition, the KMO test for sampling adequacy produces the co- efficient of 0.693 , which is more than the standard 0.5 . This finding also enhances the sampling adequacy of the factor analysis using six components. Overall, this six-factor model explains about 46 percent of the total variances. (The rotated component matrix for six-component factor analysis is given in table 3 ) 


Variable Names and Items
INFORMALITY
8. I tend to watch my grammar less in texting
than in conversations.
16. I am less concerned about people taking
things the wrong way when I write am texting than
when I have a conversation.
22. I am less concerned about how I structure my
sentences in texting than in a conversation.
29. I am less formal in texting than in a
conversation.

\section{SENSITIVITY}

18. I find it is more difficult to talk about my true feelings and thoughts in conversations than it is in texting.

19. When I am upset with someone, I would rather tell him or her in a text than in person.

20. When using texting, I feel like I can take more liberties with what I say than I can in a conversation.

27. In a conversation, I'm less likely to say things I'm unsure about than I am in texting

\section{REGULATION}

3. In a conversation, I am more likely to adjust what I say based on who I am communicating with than I am using texting.

17. I am more responsive to others in a conversation than in texting.

24. I spend less time thinking about how to respond to something I get in texting than I would if the same thing were said to me in person.

25. In texting, I find it is easier to say something harsh or critical than it is to say the same thing in person.

\section{DISCLOSURE}

23. When I write any text, I tend to focus more on what I want to say, rather than what the other person might want to say, than I do when I am having a conversation with someone.

26. I would "flame" (make an insulting or critical remark to) someone in texting before I would do it to their face.

32. I prefer to say something nice to others in person rather than writing it to them in an texting.

\begin{tabular}{llllll}
\multicolumn{7}{c}{ Factor } \\
\hline 1 & 2 & 3 & 4 & 5 & 6
\end{tabular}

Uniqueness

0.532

0.647

\section{Table 3 Rotated component matrix}




\section{(Table 3 Continued)}

\begin{tabular}{|c|c|c|c|c|c|c|c|}
\hline \multirow[t]{2}{*}{ Variable Names and Items } & \multicolumn{6}{|c|}{ Factor } & \multirow[t]{2}{*}{ Uniqueness } \\
\hline & 1 & 2 & 3 & 4 & 5 & 6 & \\
\hline \multicolumn{8}{|l|}{ EMOTIONALITY } \\
\hline \multicolumn{8}{|l|}{$\begin{array}{l}\text { personal information with someone I hardly know } \\
\text { than in text messages. }\end{array}$} \\
\hline \multicolumn{8}{|l|}{ emotions in a conversation than in texting. } \\
\hline \multicolumn{8}{|l|}{ proper use of words than I do in texting. } \\
\hline 33. When writing text, I have to take my & & & & & - & & 0.578 \\
\hline \multicolumn{8}{|l|}{ the same effect I would have in a conversation. } \\
\hline \multicolumn{8}{|l|}{ ANONYMITY } \\
\hline $\begin{array}{l}\text { 6. When I text, I feel much more like I am } \\
\text { thinking to myself than I do when I am having a } \\
\text { conversation with someone. }\end{array}$ & & & & & & 0.431 & 0.605 \\
\hline 11. I am more likely to "stretch the truth" about & & & & & & 0.625 & 0.518 \\
\hline $\begin{array}{l}\text { something in texting than I am in a conversation. } \\
\text { 13. When I talk with someone, I have a greater }\end{array}$ & & & & & & 0.688 & 0.491 \\
\hline $\begin{array}{l}\text { sense that the conversation is public than I do } \\
\text { when I am having texting exchanges. }\end{array}$ & & & & & & & \\
\hline $\begin{array}{l}\text { 28. In texting, I am less likely to be mindful of } \\
\text { the other person's position or status than when } \\
\text { talking with them. }\end{array}$ & & & & & & 0.516 & 0.588 \\
\hline
\end{tabular}

Notes. Extraction Method: Principal Component Analysis. Rotation Method: Varimax with Kaiser Normalization. Only greater than 0.35 are shown. A five-point Likert Scale response format was used.

Based on the scanned cases of the survey and the value of the 5-point Likert Scale, the cumulative responses are categorized in accordance with the six variables. Any cumulative value less than or equal to nine (9) for the variable Informality, Sensitivity, Regulation, Emotionality and Anonymity can be estimated as low level of response. Any cumulative value more than or equal to sixteen (16) for these variables may indicate high level of responses. For the variable 'Disclosure', values less than or equal to six (6) represents low and any value above ten-and-half (10.51) implies higher level of response, due to mere three items loaded for the factor.

\begin{tabular}{lllllll}
\hline Level & & & & Factor & \\
& Informality & Sensitivity & Regulation & Disclosure & Emotionality & Anonymity \\
\cline { 2 - 6 } Low & 12.8 & 8.9 & 3.6 & 3.4 & 4.9 & 5 \\
Medium & 63.5 & 58.7 & 56.2 & 47.4 & 60.3 & 56.7 \\
High & 23.7 & 32.4 & 40.1 & 49.2 & 34.8 & 38.4 \\
Total & 100 & 100 & 100 & 100 & 100 & 100 \\
\hline
\end{tabular}

Table 4 The level of conversational attributes in text-based collaborations via electronic devices

The survey indicates that near about one-fourth $(23.7 \%)$ of the respondents are less concerned about the grammar or structure of the sentences and do not worried much of whether the conversation partners taking things at the wrong way or no formality is attained. 
Almost one-third (32.4\%) of the respondents indicate, not only it is less difficult to talk and more liberating to express their words about the true feelings and thoughts in emails, but also the online conversation is more preferred at the upsetting moments as it feel certain to express in written format. Regarding the level of regulation, 40.1 percent participants imply, it is less likely to adjust and more responsive in the online conversation as they tend to think less and easy to be harsh or critical to the interaction partners. When writing an email, almost half $(49.2 \%)$ of the respondents mention that they tend to focus more on what is said, rather than what the other person might want to say, and ready to make an insulting or critical remark in an email. Regarding the share of personal information and emotional expression, one-third $(34.8 \%)$ of the participants in the survey indicates that they are more likely to control or restrain themselves in any face-to-face conversation than in an electronic mail. More than one-third $(38.4 \%)$ of the respondents indicate that when involved in text-based communication, they feel much more like thinking to own-self, ready to "stretch the truth," less likely to be mindful and hardly feel that the conversation can be publicly available. (For detail, please see table 4; for graphical presentation of the summary of the findings, please see figure 2).

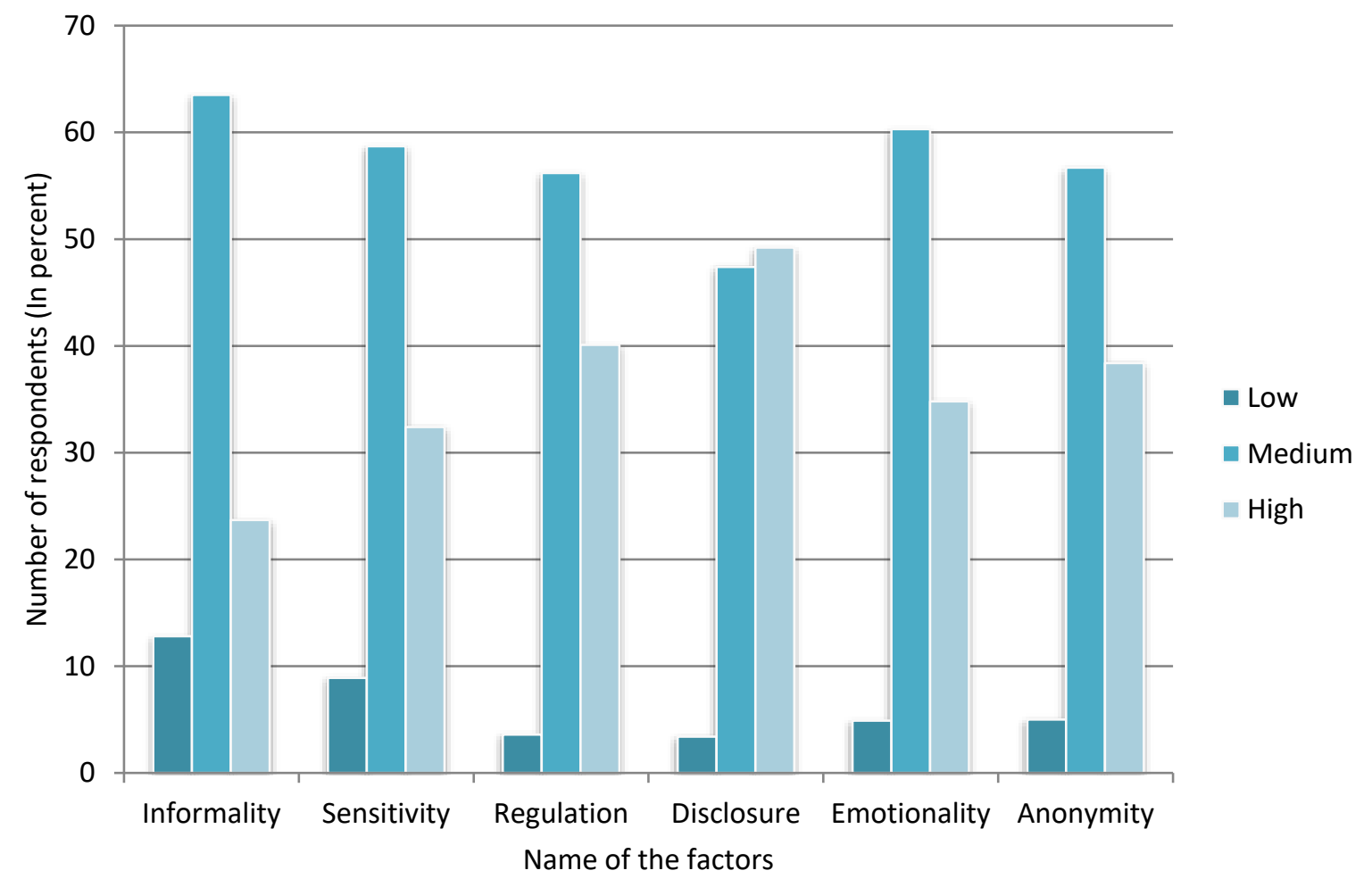

Figure 2. Attributes of the 'online-self' of the young generation in Bangladesh

\section{Conclusion}

We are living in an industrial era of growing modern technology and the communication processes have changed drastically. People now have two distinct communication channels, one the classical way of face-to-face communication, and the other more modernized computer-mediated communication. The procedural revolution of technology making people more and more linked to virtual based lives, and providing an 
outline to live in online-based curriculums. People are also getting into online associations, known as cyberspace relationships. Hence, Cyberspace is not mere a fantasized reality; it is growing rapidly as people are creating connections with real identities. However, people in their everyday lives try to create an impression to project themselves in front of individuals, whereas communicating in cyberspace and creating impression is a whole new endeavor. Appearance, voice tone, appealing, gesture and body language often complete the impression of an individual in face-to-face interaction, whereas all these cues are absent in any format of text-based correspondences. Thus, the question remains how people construct their impressions and what types of persona is being commonly constructed in computer-mediated text-based collaboration. The expanded use of the internet is common for social communications and the worldwide web has an important role to play to the construction of the 'online self'. The present study highlights the components for critical development of online self.

The internet based communication and traditional communication both have importance in showing the real-self, however, while conversing electronically, the degree of attention given to linguistic formalities like sentence structure, grammar, syntax and so on are within the moderate level of acceptance. The youth tends to be highly sensitive and cognizant during an electronic communication, nonetheless often less concerned about the potential impact of those conversations. Near about half of the respondents imply that largely the content, form, or affective characteristics of a conversation or email are tailored based on the imagined characteristics of the recipients. What is alarming is that, the level of openness or disclosure is high among the young generation. Almost the half of them indicates a high level of the willingness to disclose personal or private information in conversations or emails to the communicators. One-third of the respondents indicate that they express exaggerated or inappropriate emotional expression or affection in electronic conversation or e-mail. Further, the findings imply that over one-third of the respondents felt the form of electronic communication or email is rather impersonal or private. Therefore, the study suggests that the young generation of the nations, where technological advancement is yet to flourish is less formal, more emotionally sensitive and more open about their state of the mind. 


\section{REFERENCES}

Amichai-Hamburger, Y. (2005). Personality and the Internet. The social net: Human behavior in cyberspace, 2755.

Amichai-Hamburger, Y., Wainapel, G., \& Fox, S. (2002). "On the Internet no one knows I'm an introvert": Extroversion, neuroticism, and Internet interaction. CyberPsychology \& Behavior, 5(2), 125-128.

Bangladesh Telecommunication Regulatory Commission (BTRC) Annual Report, 2014, URL: http://www.btrc.gov.bd/annual-report Retrieved on May 12, 2015

Bangladesh Telecommunications Company Limited (BTCL), Annual Report -2012-13 URL: http://www.btcl.gov.bd/annualreport/annualreport.htm Retrieved on September 27, 2015

Boyd, D. (2007). Why youth (heart) social network sites: The role of networked publics in teenage social life. MacArthur foundation series on digital learning-Youth, identity, and digital media volume, 119-142.

Brown, S. A., Fuller, R. M., \& Vician, C. (2004). Who's afraid of the virtual world? Anxiety and computermediated communication. Journal of the Association for Information Systems, 5(2), 2.

Caplan, S. E. (2003). Preference for online social interaction a theory of problematic Internet use and psychosocial well-being. Communication research, 30(6), 625-648.

Caplan, S. E. (2005). A social skill account of problematic Internet use. Journal of communication, 55(4), 721736.

Chinn, Menzie D. and Robert W. Fairlie. (2004). The Determinants of the Global Digital Divide: A CrossCountry Analysis of Computer and Internet Penetration. Economic Growth Center. Retrieved from http://www.econ.yale.edu/growth_pdf/cdp881.pdf Retrieved on May 24, 2016

Derks, D., Bos, A. E., \& Von Grumbkow, J. (2007). Emoticons and social interaction on the Internet: the importance of social context. Computers in human behavior, 23(1), 842-849.

Donath, J. S. (1995, January). Visual Who: Animating the affinities and activities of an electronic community. In Proceedings of the third ACM international conference on Multimedia (pp. 99-107). ACM.

Douglas, K. M., \& McGarty, C. (2001). Identifiability and self-presentation: Computer-mediated communication and intergroup interaction. British journal of social psychology, 40(3), 399-416.

Ellison, N., Heino, R., \& Gibbs, J. (2006). Managing impressions online: Self-presentation processes in the online dating environment. Journal of Computer-Mediated Communication, 11(2), 415-441.

Ellison, N., Heino, R., \& Gibbs, J. (2006). Managing impressions online: Self-presentation processes in the online dating environment. Journal of Computer-Media

Epley, N., \& Kruger, J. (2005). When what you type isn't what they read: The perseverance of stereotypes and expectancies over e-mail. Journal of Experimental Social Psychology, 41(4), 414-422.

Girden, E. R. (2001). Evaluating research articles from start to finish.Thousand Oaks, Calif., Sage Publications.

Gonzales, A. L., \& Hancock, J. T. (2008). Identity shift in computer-mediated environments. Media Psychology, 11(2), 167-185.

Gujarati, D.N. (2004). Basic Econometrics, Tata McGraw Hill.

Hamilton, A. (1999, February 15). You've got male!. Time, 83.

International Telecommunication Union (ITU).ICT Facts and Figures 2014, Telecommunication Development Bureau, URL: http://www.itu.int/en/ITU-D/Statistics/Pages/facts/default.aspx Retrieved 24 May 2016.

Islam, I. (2010) Bangladesh Telecoms Sector: Challenges \& Opportunities, Asian Tiger Capital Research, November 2010. Reports available online, URL: http://www.basis.org.bd/resource/BangladeshTelecoms-Tiger.pdf Retrieved on May 24, 2016

Kelly, H. (2012) "83 million Facebook accounts are fakes and dupes", Published in CNN.com. Updated 0927 GMT (1727 HKT) August 3, 2012, retrieved on May 16, 2016. URL: http://edition.cnn.com/2012/08/02/tech/social-media/facebook-fake-accounts/

Kiesler, S., Siegel, J., \& McGuire, T. W. (1984). Social psychological aspects of computer-mediated communication. American psychologist, 39(10), 1123.

Matthews, A. R. (2006). The Technological Insularity Scale: A Scale Development (Doctoral dissertation, University of Notre Dame).

Parks, M., \& Roberts, L. (1997). The Development of Personal Relationships" Making MOOsic": On-line The Development of Personal Relationships On-line and a Comparison to their Off-line Counterparts.

Rahman, A. (2007). Access to Global Information-A case of Digital Divide in Bangladesh. URL: www.btrc.gov.bd/sites/default/files/journal_file/access_to_global_information.pdf Retrieved on May 11,2015

Rains, S. A., \& Scott, C. R. (2007). To identify or not to identify: A theoretical model of receiver responses to anonymous communication. Communication Theory, 17(1), 61-91.

Sproull, L., \& Kiesler, S. (1986). Reducing social context cues: Electronic mail in organizational communication. Management science, 32(11), 1492-1512. 
The Business Habit Blog (2015).The Number of Facebook Users in Bangladesh URL:http://www.businesshabit.com/2015/10/the-number-of-facebook-users-in.html Retrieved on September 27, 2015

Valkenburg, P. M., Schouten, A. P., \& Peter, J. (2005). Adolescents' identity experiments on the Internet. New media \& society, 7(3), 383-402.

Walther, J. B. (2007). Selective self-presentation in computer-mediated communication: Hyperpersonal dimensions of technology, language, and cognition. Computers in Human Behavior, 23(5), 2538-2557.

Wilson, J. M., Straus, S. G., \& McEvily, B. (2006). All in due time: The development of trust in computermediated and face-to-face teams. Organizational behavior and human decision processes, 99(1), 16-33. 


\section{Appendix 1}

Lists of all the items

(Adapted from Mathews, A. R. 2006)

1. I am more likely to use the correct rules of language in a conversation than in texting.

2. When writing a text, I tend to think less about how other people will react to what I am saying than when I am talking to them.

3. In a conversation, I am more likely to adjust what I say based on who I am communicating with than I am using texting.

4. In a conversation, I am less likely to share personal information with someone I hardly know than in text messages.

5. I am more likely to control or restrain my emotions in a conversation than in texting.

6. When I text, I feel much more like I am thinking to myself than I do when I am having a conversation with someone.

7. I might say things to superiors (for example, professors or managers) in texting that I would not say to them in a conversation.

8. I tend to watch my grammar less in texting than in conversations.

9. In a conversation, I am more likely to consider how what I say will be taken from the other person's point of view than when I am texting.

10. I am less likely to pay attention to the tone of what I am saying in text than when I am having a conversation.

11. I am more likely to "stretch the truth" about something in texting than I am in a conversation.

12. It is easier to "go off" on someone in texting messages than it is in a conversation.

13. When I talk with someone, I have a greater sense that the conversation is public than I do when I am having texting exchanges.

14. I am less likely to be conscious of proper etiquette in texting than in conversations.

15. In a conversation, I pay more attention to the proper use of words than I do in texting.

16. I am less concerned about people taking things the wrong way when I write am texting than when I have a conversation.

17. I am more responsive to others in a conversation than in texting.

18. I find it is more difficult to talk about my true feelings and thoughts in conversations than it is in texting.

19. When I am upset with someone, I would rather tell him or her in a text than in person.

20. When using texting, I feel like I can take more liberties with what I say than I can in a conversation.

21. I am more likely to send an identical texting to peers and superiors (for example, professors or managers) than I am to speak in person with them in an identical way.

22. I am less concerned about how I structure my sentences in texting than in a conversation.

23. When I write any text, I tend to focus more on what I want to say, rather than what the other person might want to say, than I do when I am having a conversation with someone.

24. I spend less time thinking about how to respond to something I get in texting than I would if the same thing were said to me in person.

25. In texting, I find it is easier to say something harsh or critical than it is to say the same thing in person.

26. I would "flame" (make an insulting or critical remark to) someone in texting before I would do it to their face.

27. In a conversation, I'm less likely to say things I'm unsure about than I am in texting

28. In texting, I am less likely to be mindful of the other person's position or status than when talking with them.

29. I am less formal in texting than in a conversation.

30. I am less concerned about accidentally offending or hurting someone's feelings in texting than I am when talking with them.

31. I need to be more careful about what I say to someone in person than in texting.

32. I prefer to say something nice to others in person rather than writing it to them in texting.

33. When writing text, I have to take my emotional expression up a notch or two to achieve the same effect I would have in a conversation.

34. I never feel quite as personally connected to someone when texting as I do in a conversation.

35. I am more reserved when conversing with superiors (for example, professors or managers) than when texting them. 